\title{
Imaging of Degenerative Pathologies of the Lumbar Spine: Professional Habits in Some Hospitals in Cameroon
}

\author{
Mohamadou Aminou', Yannick Onana Richard', Mbozo'o Nvondo Samuel', \\ Neossi Nguena Mathurin ${ }^{2}$, Aissata Bintou Moctar ${ }^{3}$, Ngo Nyemeg Celenaie Claude ${ }^{4}$, \\ Mbo Amvene Jeremie ${ }^{1}$
}

\author{
${ }^{1}$ Department of Radiology and Medical Imaging, Faculty of Medicine and Biomedical Sciences, University of Ngaoundere, \\ Ngaoundere, Cameroon \\ ${ }^{2}$ Department of Biomedical Sciences, Faculty of Science, University of Ngaoundere, Ngaoundere, Cameroon \\ ${ }^{3}$ Department of Radiology and Medical Imaging, Maroua Regional Hospital, Maroua, Cameroon \\ ${ }^{4}$ Department of Radiology and Medical Imaging, Laquintinine Hospital, Douala, Cameroon \\ Email: mohamadou@live.co.uk
}

How to cite this paper: Aminou, M., Richard, Y.O., Samuel, M.N., Mathurin, N.N., Moctar, A.B., Claude, N.N.C. and Jeremie, M.A. (2021) Imaging of Degenerative Pathologies of the Lumbar Spine: Professional Habits in Some Hospitals in Cameroon. Journal of Biosciences and Medicines, 9, 143-154.

https://doi.org/10.4236/jbm.2021.98012

Received: June 25, 2021

Accepted: August 23, 2021

Published: August 26, 2021

Copyright $\odot 2021$ by author(s) and Scientific Research Publishing Inc. This work is licensed under the Creative Commons Attribution International License (CC BY 4.0).

http://creativecommons.org/licenses/by/4.0/

(c) (i) Open Access

\begin{abstract}
Background: The lumbar spine is the portion most frequently involved in degenerative pathologies. Everyone will suffer one day from "low back pain". These pathologies are very frequent: epidemiological studies have shown that $65 \%$ to $90 \%$ of the general population could be affected by low back pain (lumbago) which could become chronic at acertain stage or could be complicated ( $2 \%$ to $4 \%)$ of cases could end up affecting nerve roots. Chronic low back pain causes a major public health problem in terms of morbidity and socioeconomic repercussions. Purpose: The overall purpose of this study is to evaluate the professional habits of exam applicants in case of degenerative pathologies of the lumbar spine, to Appreciate the knowledge of clinicians on the usefulness of medical imaging techniques in the event of suspicion of a degenerative pathology of the lumbar spine and finally to evaluate if the professional habits of requesting examinations in Cameroon comply with the Recommendations for Clinical Practice. Methods: A cross-sectional and descriptive study was used and was based on questionnaires distributed to those practitioners who requested for these diagnostic medical imaging studies and procedures at Yaoundé General Hospital (HGY), Yaoundé Central Hospital, La Cathédrale Medical Center, Yaoundé University Teaching Hospital, the Douala General Hospital, the Laquintinie Hospital of Douala, the Military Hospital of Douala, the Daniel Muna Memorial Clinic of Douala, the International Center for Clinical and Medicine Imaging, the Ngaoundere Regional
\end{abstract}


Hospital and the Protestant Hospital of Ngaoundere (HPN), from April 2020 to March 2021. Data collected was processed and analyzed via Epi Info version 12.0 and the statistical test used for correlation was $\mathrm{Chi}^{2}$. Results: 137 practitioners were retained among whom, 90 were male and 47 females, their average age being 46 years with working experience less than 5 years $(35.8 \%)$. The results obtained show that parameters such as availability and accessibility of the required diagnostic medical imaging modalities could greatly influence the examination prescription. On the contrary, few prescribers were less interested in the costs and secondary effects due to irradiation and the invasiveness of these examinations. Professional habits of those who requested these examinations were in majority closer in line with the recommended clinical practices. However, an average of $43.78 \%$ of prescribers never followed recommendations nor applied them. On the other hand, knowledge and the application of these recommendations increased as the prescriber's working experience too increased. Up to $54.47 \%$ of prescribers were not aware of those recommendations about requesting these examinations. Conclusion: Our results indicate that Medical Diagnostic Imaging techniques are not judiciously and optimally exploited in the diagnosis of degenerative pathologies of the lumbar spine and it would be necessary to establish recommendations for clinical practice adapted to Cameroonian realities.

\section{Keywords}

Lumbar Spine, Medical Imaging, Degenerative Pathologies, Professional Habits, Recommendations

\section{Introduction}

Degenerative pathologies are conditions linked to the wear and tear of the intervertebral disc [1]. Over time, degeneration progresses with the appearance of tears in the fibrous ring around the disc [2]. The center of the disc can then migrate through the thickness of this fibrous ring and cause acute or chronic low back pain.

In 2009, a study was carried out in Cameroon in the Rheumatology and Neurosurgery departments of the Douala General Hospital on chronic low back pain and revealed that degenerative lumbar damage represents $94.9 \%$ of the causes of chronic low back pain [3]. (M. S. DOUALLA et al., 2009). The seriousness of these conditions lies in their evolutionary aspects which can lead to motor complications up to paralysis and sensory complications up to hypoaesthesia and genital and sphincter complications [4].

In Africa, low back pain is the main reason for rheumatological consultation with a prevalence of 35.34\% in Togo [5] (M. Mijiyawa et al., 2000). It, therefore, appears imperative to limit their evolutionary aspects in patients, by promoting early diagnosis for optimal management. Research on the clinical practice of the degenerative pathologies of the lumbar spine is rare, and very few were reported 
in the literature, and none focusing on the professional habits of the applicants.

The diagnosis of degenerative pathologies of the lumbar spine begins at the clinical manifestation, then extends to medical imaging techniques to discover the causes of symptoms. It is the clinicians who direct the diagnosis and who request the medical imaging examinations that should be appropriate for the diagnosis of pathologies suspected on clinical examination [6].

However, the development of medical imaging technologies makes it difficult to choose the appropriate techniques and applicants for examinations have a delayed or even insufficient apprehension of technological innovation, which could lead to an extension of the diagnostic time of a degenerative pathology and worsen the prognosis.

The main objective of this research is to study the professional habits of applicants for examinations of degenerative pathologies of the lumbar spine. And specifically to appreciate the knowledge of clinicians on the usefulness of medical imaging techniques in suspicion of a degenerative pathology of the lumbar spine, to describe the different medical imaging techniques required when the degenerative pathologies of the lumbar spine are suspected, to establish the relationship between the professional habits of clinicians in Cameroon and the Recommendation for Clinical Practice and to establish a correlation between the professional characteristics of clinicians and their choice of requests for medical imaging examinations.

\section{Materials and Methods}

This cross-sectional and descriptive study was carried out in 14 reference hospitals in three main cities of the country namely: Yaoundé General Hospital (HGY), Yaoundé Central Hospital, La Cathédrale Medical Center, Yaoundé University Teaching Hospital, the Douala General Hospital, the Laquintinie Hospital of Douala, the Military Hospital of Douala, the Daniel Muna Memorial Clinic of Douala, the International Center for Clinical and Medicine Imaging, the Ngaoundere Regional Hospital and the Protestant Hospital of Ngaoundere (HPN), from April 2020 to March 2021. A consecutive non-probabilistic exhaustive and consecutive sampling technique was used.

\section{The Study Population}

Initially, the number of applicants from hospitals in each region to be recruited was determined by the LORENTZ formula:

$$
N=(z \alpha)^{2} \times p \cdot q \div d^{2}
$$

$N=$ Sample size;

$Z=$ value of the normal distribution $\alpha=$ threshold for rejecting the null hypothesis;

$P=$ prevalence of degenerative spine pathologies $q=1-P$;

$d=$ level of precision; 
We consider: $\alpha=0.05$ hence $Z \alpha=1.96 ; d=10 \%$.

Failing to use this formula, we were satisfied with an exhaustive sample, the number of exam applicants from hospitals in each region to recruit was randomly determined based on their availability during our recruiting period. Were included in our study, any applicant for low back pain imaging examinations, regardless of age, sex, qualification, grade, or seniority, and have agreed to sign our informed consent form. These are general practitioners, specialist physicians, physiotherapists, and State Registered Nurses.

\subsection{Participant}

Our target population consisted of general practitioners, specialist physicians (rheumatologists, neurologists, surgeons, neurosurgeons, orthopaedists) and any other requestor of examinations that we met during our data collection, namely physiotherapists and State Registered Nurses who are receiving patients suffering from low back pain and/or radicular pain any applicant for medical imaging examinations, regardless of age, sex, qualification, grade or seniority, and have agreed to sign our informed consent form.

\subsection{Inclusion Criteria}

Were included in our study, any applicant for medical imaging examinations in case of suspected degenerative pathology of the lumbar spine, regardless of age, sex, qualification, grade, or seniority, and have agreed to sign our inform consent form.

\subsection{Variables}

To achieve the objectives of the study, the following variables were collected:

\subsubsection{For Exam Applicants}

- Age;

- Profession;

- Rank;

- Working Experience in years;

- Hospital.

\subsubsection{Degenerative Pathologies of the Spine}

- Diagnostic means available within the hospital;

- Choice of imaging techniques based on clinical signs and suspected pathologies.

\subsubsection{Medical Imaging Techniques}

- Reference techniques in the context of degenerative pathologies of the spine;

- Justification for the choice of application.

\subsection{Collection Technique}

The researcher designed a questionnaire to be used and pre-tested it at the 
Ngaoundere Regional Hospital.

Data were collected after the authorizations from the administration of the targeted health structures. Once these authorizations had been obtained, the questionnaires were given to the exam applicants present in these structures.

Demographic data such as age, profession, rank, specialties, and number of years in the profession were assessed followed by, diagnostic means available within the hospital, the choice of imaging techniques based on clinical signs, and suspected pathologies.

\subsection{Data Analysis}

Data were collected using a questionnaire and were analyzed using Microsoft Excel 2016, EpiInfo 2.0, and the SPSS 10.0. $P$-values $<0.05$ indicate statistical significance.

\section{Results}

Our studied population was 137 applicants, distributed according to their age, grade, seniority, and hospital structure. The general partitioners were the most represented with $38 \%$ followed by the physicians with $35 \%$ while professors and state registered nurses were less represented with $2 \%$ respectively (Table 1 ). The age group 30 - 40 were most represented with $35 \%$ and between 60 - 70 were the less represented with $2.9 \%$ as shown in Figure 1.

The majority of test seekers do not know exactly what Imaging diagnostic means are available in the hospitals where they work, with a rate of $59.12 \%$ of incorrect answers (Table 2).

Table 1. Distribution of grade according to seniority.

\begin{tabular}{cccccccc}
\hline Seniority/Grade & Non-Response & Less than 5 & $5-10$ & $10-15$ & $15-20$ & $20-25$ & \\
\hline $\begin{array}{c}\text { Health } \\
\text { Technicians }\end{array}$ & 0 & 5 & 2 & 0 & 0 & 0 & $5.1 \%$ \\
Resident & 0 & 10 & 13 & 0 & 0 & 0 & $16.8 \%$ \\
$\begin{array}{c}\text { General } \\
\text { Practitioner }\end{array}$ & 1 & 29 & 9 & 3 & 4 & 6 & $38.0 \%$ \\
Physicians & 2 & 5 & 11 & 11 & 10 & 10 & $35.8 \%$ \\
Professors & 0 & 0 & 0 & 0 & 0 & 3 & $2.2 \%$ \\
State R Nurses & 0 & 0 & 0 & 1 & 0 & 2 & $2.2 \%$ \\
Total & $2.2 \%$ & $35.8 \%$ & $25.6 \%$ & $11.0 \%$ & $10.2 \%$ & $15.3 \%$ & $100 \%$ \\
\hline
\end{tabular}

Table 2. Knowledge of applicants on diagnostic imaging means available in their hospital structure.

\begin{tabular}{ccc}
\hline Response & Frequency & Percentage \\
\hline Right & 56 & $40.88 \%$ \\
Wrong & 81 & $59.12 \%$ \\
Total & 137 & $100 \%$ \\
\hline
\end{tabular}




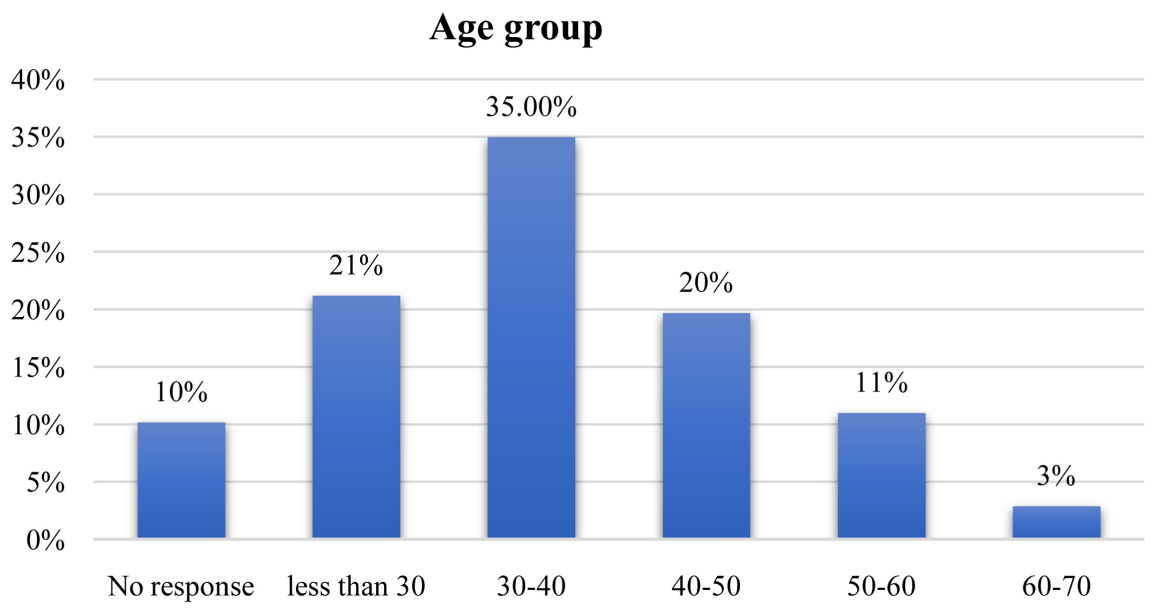

Figure 1. Distribution of the population according to age.

The majority of exam prescribers $(55.50 \%)$ do not automatically request an examination for low back pain because they prescribe based on the clinical data (48.86\%). 100\% of professors do not automatically request an imaging examination for low back pain, followed by $71.43 \%$ of physicians. The dependence is significant, $\mathrm{chi}^{2}=18.74$ (Figure 2).

They were a significant dependence between the clinical and imaging request $(\mathrm{p}=0.01)$ (Table 3$)$. The first-line examination requested when a degenerative pathology of the lumbar spine is suspected is the standard X-ray (88.32\%) with the main reasons being availability $(37.83 \%)$ and efficiency $(35.86 \%)$. There is a significant difference with $\mathrm{p}=0.01$ (Table 4 ). With a rate of $40.29 \%$, CT is the most prescribed examination when canal stenosis is suspected, with the main reasons for effectiveness (50.35\%) and essential (28.37\%) as shown in (Table 5).

Finding reported that $55.47 \%$ of the applicants are not aware of the Recommendations of Clinical Practice (Table 6), and the majority of whom (44.74\%) are general practitioners and a majority of applicants (47.37\%) with seniority of fewer than 5 years (Table 7). 73.46\% of exam applicant with less than 5 years of experience are unfamiliar with RCP/GBU. Dependence is very significant, $\mathrm{chi}^{2}=$ 19.68 (Table 8).

The most represented age group is 30 to 40 (35\%), and the least represented age group is $60-79$ yards with the extremes varying between 23 and 69 years.

Our study population consists mainly of general practitioners with a rate of $38 \%$ and less than five years of working experience, with a rate of $35.80 \%$.

The majority of exam applicants do not know exactly what diagnostic means are available in the hospitals where they work, with a rate of $59.12 \%$ of incorrect answers.

The majority of exam prescribers (55.50\%) do not automatically request an examination for low back pain because they prescribe based on the clinical data (48.86\%). They were a significant dependence between the clinical and imaging request $(\mathrm{p}=0.01)$.

The first-line examination is requested when a degenerative pathology of the 


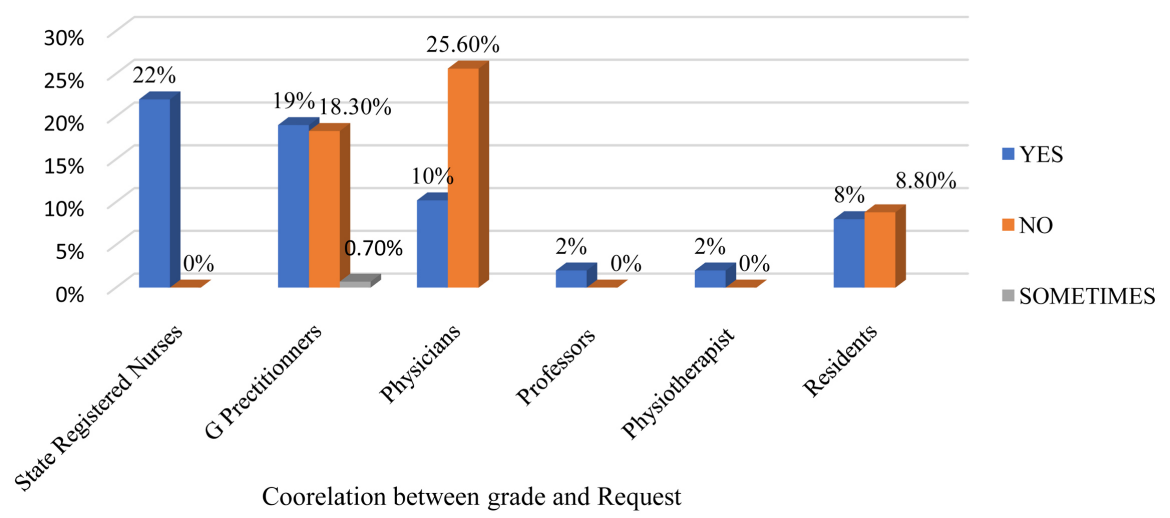

Figure 2. Correlation between the choice of examination request and the grade.

Table 3. Motivations for the automatic choice of an imaging test in low back pain.

\begin{tabular}{ccccc}
\hline Motivation of the request & Yes & No & Sometimes & TOTAL \\
\hline Efficient & 33 & 0 & 0 & 33 \\
Essential & 32 & 0 & 1 & 33 \\
Available & 27 & 0 & 1 & 28 \\
Less expensive & 9 & 0 & 0 & 9 \\
Unavailable & 0 & 4 & 0 & 4 \\
Radiating & 0 & 21 & 0 & 21 \\
Invasive & 0 & 3 & 0 & 3 \\
Expensive & 0 & 11 & 0 & 11 \\
Depend upon the symptoms & 0 & 43 & 1 & 44 \\
Other & 2 & 6 & 0 & 8 \\
\hline
\end{tabular}

Table 4. Correlation of first-line examinations and reasons for choosing these exams.

\begin{tabular}{ccccccc}
\hline $\begin{array}{c}\text { Motivations/First } \\
\text { exam Requested }\end{array}$ & $\begin{array}{c}\text { No } \\
\text { response }\end{array}$ & Efficient & Essential & Available & Costless & Other \\
\hline No response & 1 & 0 & 0 & 0 & 0 & 0 \\
X ray & 2 & 57 & 40 & 87 & 40 & 4 \\
CT & 0 & 8 & 1 & 5 & 2 & 1 \\
MR & 0 & 1 & 0 & 1 & 0 & 0 \\
PET Scan & 0 & 2 & 0 & 1 & 1 & 0 \\
\hline
\end{tabular}

lumbar spine is suspected is the standard X-ray (88.32\%) with the main reasons being availability (37.83\%). Dependence is very significant, $\mathrm{chi}^{2}=93.44$.

With a rate of $64.05 \%$, the standard $\mathrm{X}$-ray is the most prescribed examination when low back osteoarthritis is suspected, with the main reasons for efficiency $(35.86 \%)$ and availability (27.43\%). Dependence is very significant, $\mathrm{chi}^{2}=$ 137.87 .

With a rate of $40.29 \%$, CT is the most prescribed examination when canal stenosis is suspected, with the main reasons for effectiveness (50.35\%) and essential (28.37\%). Dependence is very significant, $\mathrm{chi}^{2}=377.44$. 
Table 5. Examinations requested in the event of suspected lumbar osteoarthritis and reason for the choice.

\begin{tabular}{ccccccc}
\hline $\begin{array}{c}\text { Motivations/ } \\
\begin{array}{c}\text { Suspicion of lumbar } \\
\text { osteo arthritis }\end{array}\end{array}$ & $\begin{array}{c}\text { No } \\
\text { response }\end{array}$ & Efficient & Essential & Available & Costless & Other \\
\hline No Response & 0 & 0 & 0 & 0 & 0 & 1 \\
X-ray & 6 & 85 & 41 & 65 & 38 & 2 \\
CT scan & 2 & 45 & 27 & 22 & 4 & 1 \\
Myelography & 1 & 1 & 0 & 0 & 0 & 0 \\
Scintigraphy & 0 & 1 & 1 & 0 & 0 & 0 \\
MRI & 1 & 11 & 7 & 4 & 0 & 0 \\
SRG & 1 & 1 & 0 & 1 & 1 & 0 \\
\hline
\end{tabular}

Table 6. Examinations requested in the event of suspected ductal stenosis and reason for the choice.

\begin{tabular}{|c|c|c|c|c|c|c|}
\hline $\begin{array}{l}\text { Motivations/ } \\
\text { Suspicion of } \\
\text { canal stenosis }\end{array}$ & $\begin{array}{c}\text { No } \\
\text { response }\end{array}$ & Efficient & Essential & Available & Costless & Other \\
\hline No Response & 3 & 0 & 0 & 0 & 0 & 4 \\
\hline $\mathrm{X}$ ray & 0 & 19 & 16 & 14 & 0 & 0 \\
\hline CT scan & 0 & 71 & 40 & 28 & 2 & 0 \\
\hline Myelography & 0 & 33 & 6 & 5 & 2 & 0 \\
\hline Scintigraphy & 0 & 6 & 3 & 3 & 0 & 0 \\
\hline MRI & 0 & 41 & 23 & 9 & 1 & 0 \\
\hline SRG & 0 & 12 & 6 & 1 & 2 & 0 \\
\hline
\end{tabular}

Table 7. Awareness of recommendations for clinical practice according to grade.

\begin{tabular}{ccccccc}
\hline Grade/RPC/GBU & $\begin{array}{c}\text { Health } \\
\text { Technicians }\end{array}$ & Resident & $\begin{array}{c}\text { General } \\
\text { Practitioners }\end{array}$ & Physicians Professor Registered TOTAL \\
Nurses
\end{tabular}

Table 8. Awareness of recommendations for clinical practice according to the number of years of experience.

\begin{tabular}{cccccccc}
\hline Experience/RCP & $\begin{array}{c}\text { No } \\
\text { Response }\end{array}$ & $\begin{array}{c}\text { Less than } \\
5 \text { years }\end{array}$ & $\begin{array}{c}5 \text { to } 10 \\
\text { years }\end{array}$ & $\begin{array}{c}10 \text { to } 15 \\
\text { years }\end{array}$ & $\begin{array}{c}15 \text { to } 20 \\
\text { years }\end{array}$ & $\begin{array}{c}\text { More } \\
\text { than 20 } \\
\text { years }\end{array}$ & TOTAL \\
\hline Yes & 3 & 13 & 14 & 11 & 10 & 10 & 61 \\
No & 0 & 36 & 21 & 4 & 4 & 11 & 76 \\
TOTAL & 3 & 49 & 35 & 15 & 14 & 21 & 137 \\
\hline
\end{tabular}




\section{Recommendations for Clinical Practice}

Recommendation for Clinical Practice are statements that include guidelines intended to optimize patient care that are informed by a systematic review of evidence and an assessment of the benefits and harms of alternative care options. In our study, $55.47 \%$ of applicants do not know the RCP with a majority of $44.74 \%$ ) of general practitioners and a majority of $47.37 \%$ of applicants with seniority of fewer than 5 years. The dependence is significant, chi $^{2}=14.97$.

$73.46 \%$ of exam seekers with less than 5 years of experience are unfamiliar with RCP/GBU. Dependence is very significant, $\mathrm{chi}^{2}=19.68$.

\section{Discussion}

According to the ANAES recommendations of 1998, diagnostic imaging for low back pain is not only usually unnecessary (except in the case of suspicion of symptomatic low back pain), but can worsen the prognosis and impact on the patient's living conditions [7]. For this reason, guidelines were developed in 1995 and adapted by the French Society of Radiology (SFR) in 2005 into Recommendations for Clinical Practice (RPC) to prioritize and optimize prescriptions [7] [8]. These recommendations, far from being absolute acts, must be taken into account as the basis for requesting and guide clinicians in the choice of medical imaging techniques to request.

In developing countries like Cameroon, several imaging techniques are unavailable. This leads us to believe that other parameters, in addition to the development of medical imaging technologies, could influence the clinician who would be forced to order unnecessary or poorly performing imaging examinations and not examinations with the best possible performance.

In our study, the most represented age group is that of 30 to 40 (35\%) and that of 60 to 70 years is the least represented. These results are similar to those obtained during the general census of health sector personnel in Cameroon carried out by the Ministry of Public Health in 2011 [9], which show that the most representative age group of health personnel is that of 31 to 40 years old and the one over 65 the least represented.

Most patients are likely to be consulted by physicians rather than a general practitioner or other health professionals, there for the request of medical imaging in case of low back pain is mostly from them. They do not request automatically for the imaging examination of the patient according to Table 1.

The most represented grade is that of general practitioners with a rate of $38 \%$ followed by specialists with a rate of $35.8 \%$. These results are different from those obtained during the general census of health sector personnel in Cameroon carried out by the Ministry of Public Health in 2011, which shows a majority grade of nurses with a rate of $49.61 \%$, followed by paramedical personnel with a rate of $11.85 \%$. This difference can be explained by the fact that this census was carried out throughout the Cameroonian territory when our target population consisted of applicants for imaging examinations from the most fre- 
quented public hospitals and clinics. In these types of facilities, nurses and paramedical staff (physiotherapists) rarely prescribe.

The majority of applicants do not know exactly what diagnostic means are available in the hospitals where they work, with a rate of $59.12 \%$ of incorrect answers. This result is different from that of [10] of MG. TSEGAING in 2014, which shows that $20 \%$ of doctors do not know exactly the imaging means available in their health structure [11]. This problem can be explained by a lack of correlation of information between the medical imaging service and other services in health facilities.

The majority of the applicant (55.50\%) do not automatically order an examination for low back pain. A positive correlation was found between these trends and the reasons for these choices: $48.86 \%$ of the reasons given are prescriptions based on the clinical symptoms of low back pain and $23.86 \%$ take into account irradiation. A positive correlation was found between this trend and the reasons for these choices: This result agrees with the National Research Council, 2001, [12] whose clinical experience shows the importance of the distinction between acute or subacute and chronic disorders, on the one hand, and between potentially reversible transient disorders and proven and not very reversible disorders on the other hand, when treating common low back pain [13].

However, the rate of $43.04 \%$ of applicants who automatically prescribe for low back pain is not to be overlooked. The main reasons given are efficiency (32.04\%), essential (31.07\%), and availability (26.21\%). It has been reported that (61.30\%) automatically order an examination for radiculalgia. A positive correlation was found between this trend and the reasons for these choices: The main reasons given are the essential (40.5\%) and the concern for efficiency (39.67\%).

Furthermore, the rate of $37.96 \%$ of applicants who do not automatically prescribe for radiculalgia is not to be overlooked. The main reasons given are the prescription according to the clinical data $(46.03 \%)$, the consequences of the examination (Irradiation and invasive examination with a rate of $19.05 \%$ ), and the cost (15.87\%).

It has been reported that standard radiography is the examination most often requested as a first-line examination when degenerative pathologies of the lumbar spine are suspected with a rate of $88.32 \%$, followed by CT $(5.84 \%)$ and scintigraphy (2.19\%). Not having specified the type of degenerative pathology, these results agree with the opinion of J. JOFFRE [14] who stipulates that when the warning signs have a limited orientation value: it is necessary to adopt a progressive strategy, starting with Simple unscrambling explorations, such as conventional radiography, allowing for more precise orientation and determination of subsequent diagnostic steps [15].

For the suspicion of lumbar osteoarthritis, standard radiography (64.05\%) and CT (27.29\%) are the most requested examinations. A similar result was obtained from a study done in the university hospital of Toulouse in France [16]. This is according to the RCP. For suspected ductal stenosis, these are CT (40.29\%) and 
MRI (21.14\%) and the reason is the ability of those imaging modalities to have a great spatial resolution. For the herniated disc, these are CT (50.13\%) and MRI (20.13\%). For a suspected spondylolisthesis, these are the standard X-ray (50.46\%) and CT (32.2\%). A positive correlation was found between the first-line examination requested when a degenerative pathology of the lumbar spine was suspected and the reasons for this request. The main reasons given are availability (37\%), efficiency $(26.77 \%)$, cost $(16.93 \%)$, and essential $(16.14 \%)$. These results show that the examinations requested are mainly a function of the availability of techniques [17].

For a suspected herniated disc, the examination requested mainly in the first intention, without taking into account the availability of devices, is CT with a rate of $65 \%$ and in second-line MRI with a rate of $48.2 \%$.

\section{Conclusion}

We conducted a descriptive and cross-sectional study on the professional habits of 137 applicants for examinations, in case of suspected degenerative pathologies of the lumbar spine, affected in fourteen health structures in the cities of Douala, Yaoundé, and Ngaoundere. The majority age group for exam applicants was 30 to 40 years old with less than 5 years of seniority. The diagnostic means of medical imaging were not known to the majority of applicants who were also not aware of the Recommendations for Clinical Practice.

\section{Limitation of the Study}

The main problem encountered during our research was obtaining the authorizations for data collection in the target health structures causing a considerable slowdown in our data collection. The reluctance of several applicants who felt our study was inadequate for our training, lastly the unavailability of applicants who were too busy to complete our questionnaires.

\section{Acknowledgements}

Our sincere gratitude to the administrative and medical imaging staff for their collaboration and support during our study. We also thank all the respondents who agreed and sign the inform concern to participate in this research.

\section{Conflicts of Interest}

The authors declare no conflicts of interest regarding the publication of this paper.

\section{References}

[1] Enow-Orock, G. (2006) Aging Spine Center-Guide du Patient Low Back Pain.

[2] Avimadje, A.M. et al. (2003) Facteurs de risque de la lombalgie par discopathie dégénérative lombaire au Bénin. Synoviale, 122, 13-16.

[3] ANAES (1998) Agence Nationale d'Accréditation et d'Evaluation en Santé. L'imagerie 
dans la lombalgie commune de l'adulte. Agence Nationale d'Accréditation et d'Evaluation en Santé, Paris.

[4] ANAES (2005) Prise en charge masso-kinésithérapique dans la lombalgie commune. Agence Nationale d'Accréditation et d'Evaluation en Santé, Paris.

[5] Netter, F.H. (2004) Atlas d'anatomie humaine, MASSON 3e édition, 2004, Paris, planche 148, Traduction de P. KAMINA. Nouvelle méthode de diagnostique radiologique Memo, 10, 175-180.

[6] Frank, J., Sinclair, S., Hoggjohnson, S., Shannon, H., Bombardier, C., Beaton, D., et al. (1998) Preventing Disability from Work-Related Low-Back Pain-New Evidence Gives New Hope-If We Can Just Get All the Players Onside. Canadian Medical Association Journal, 158, 1625-1631.

[7] Société Française de Radiologie (2013) Guide du bon usage des examens d'imagerie médicale-Recommandations pour les professionnels de Santé.

[8] Mellin, G., et al. (1990) A Controlled Study on the Outcome of Inpatient and Outpatient Treatment of Low Back Pain. Part II. Long-Term Effects on Physical Measurements. Journal of Rehabilitation Medicine, 22, 189-194.

[9] Rouviere, H. (1975) Anatomie Humaine, Description Topographique et Fonctionnelle. MASSON, Paris, p. 720.

[10] INSERM (2000) Lombalgies en milieu professionnel. Quels facteurs de risque et quelle prévention? Expertise Collective, INSERM.

[11] Lacronique, J.F. (1991) Le coût du mal de dos. Les Assises Internationales du dos, Grenoble, 7-12.

[12] Dougados, M. (2000) Les rhumatismes en 100 questions Arthrose en 100 questions. Institut de Rhumatologie, Paris.

[13] Chevallier, J.M., et al. (1998) Anatomie: Neuro-Anatomie Tome 4 Med-Science Flammarion Paris. $1^{\text {ère }}$ édition, Flammarion, Paris, 6.

[14] Mukaya, J., et al. (2012) Profil radio-clinique de la pathologie rachidienne. Larousse médical.

[15] Doualla, M.S., et al. (2009) Présentation clinique et radiologique de la lombalgie chronique en consultation hospitalière a douala Cameroun.

[16] ANAES (2000) Agence nationale d'accréditation et d'évaluation en santé. Prise en charge diagnostique et thérapeutique des lombalgies et lombosciatiques communes de moins de trois mois d'évolution. Recommandations de bonnes pratiques., Agence Nationale d'Accréditation et d'Evaluation en Santé, Paris .

[17] Mijiyawa, M., et al. (2000) Low Back Pain in Hospital out Patients in Lomé (Togo). Joint Bone Spine, 67, 533-538. https://doi.org/10.1016/S1297-319X(00)00204-9

\section{Appendix}

$\underline{\text { https://docs.google.com/document/d/1rieqj5668Nyy_6jbyT7butpaDy8bauJh/edit }}$ 